\title{
CD44v6, MMP-7 and nuclear Cdx2 are significant biomarkers for prediction of lymph node metastasis in primary gastric cancer
}

\author{
HIROKAZU OKAYAMA ${ }^{1}$, KENSUKE KUMAMOTO ${ }^{1}$, KATSUHARU SAITOU ${ }^{1}$, SUGURU HAYASE ${ }^{1}$, \\ YASUHIDE KOFUNATO ${ }^{1}$, YU SATO ${ }^{1}$, KOTARO MIYAMOTO ${ }^{1}$, IZUMI NAKAMURA ${ }^{1}$, \\ SHINJI OHKI $^{1}$, KOUJI SEKIKAWA ${ }^{2}$ and SEIICHI TAKENOSHITA ${ }^{1}$ \\ ${ }^{1}$ Department of Organ Regulatory Surgery, Fukushima Medical University School of Medicine, 1 Hikarigaoka, Fukushima \\ 960-1295; ${ }^{2}$ Department of Surgery, Kawasaki-Saiwai Hospital, 39-1 Kawasaki, Kanagawa 212-0021, Japan
}

Received May 26, 2009; Accepted July 3, 2009

DOI: 10.3892/or_00000496

\begin{abstract}
The aim of this study was to examine the expression of CD44v6, CD54, Cdx2, CXCL5, Cyclin B1, MMP-7, nm23, RCAS1 and Survivin in primary gastric cancer and to investigate whether these molecules were useful in predicting the lymph node status. They were selected as candidates for indicators of lymph node metastasis from various kinds of cancer-associated genes reported previously. In 135 cases of radically resected primary gastric adenocarcinoma, we investigated the association between the expression of these molecules and clinocopathologic factors by immunohistochemistry. The results revealed that the expression of CD44v6 and MMP-7 were significantly associated with lymph node status. By contrast, nuclear $\mathrm{Cdx} 2$ expression was found to be inversely correlated with lymph node metastasis. Moreover, multivariate analysis demonstrated that CD44v6, MMP-7 and nuclear Cdx2 were independent predictors for lymph node status. In conclusion, our results suggest that positive expression of both CD44v6 and MMP-7, and negative expression of nuclear $\mathrm{Cdx} 2$ may serve as powerful predictors of lymph node metastasis in gastric cancer. Combined evaluation of these markers could be further useful to predict lymph node status clinically.
\end{abstract}

\section{Introduction}

Survival of patient with gastric cancer has improved with the development of diagnostic and therapeutic techniques over the past few decades. However, gastric cancer still remains a major cause of cancer death worldwide (1). Lymph node status

Correspondence to: Dr Seiichi Takenoshita, Department of Organ Regulatory Surgery, Fukushima Medical University School of Medicine, 1 Hikarigaoka, Fukushima 960-1295, Japan

E-mail: takenoss@fmu.ac.jp

Key words: CD44v6, MMP-7, Cdx2, lymph node metastasis, gastric cancer is one of the most important prognostic factors for patients with radically resected gastric cancer (2-4). The appropriate extension of lymphadectomy on the basis of accurate lymph node status for surgical treatment is still controversial $(5,6)$. In recent years, minimally invasive therapies, including endoscopic resection and laparoscopic surgery, have been performed frequently $(7,8)$. Therefore, predicting lymph node status in patients with gastric cancer is very important in treatment decision. Although numerous molecular markers indicating the lymph node spread in gastric cancer have been investigated, none of them is sufficient enough to be implemented in the clinical setting to predict lymph node status.

In this study, nine biomarkers including CD44v6, CD54, Cdx2, CXCL5, Cyclin B1, MMP-7, nm23, RCAS1 and Survivin, were selected as candidates for predicting lymph node status from many cancer-associated genes, which had shown to be correlated with lymph node metastasis. We performed immunohistochemical analysis in 135 cases of primary gastric cancer, and analyzed the relationship between these biomarkers expression on cancer tissues and clinocopathologic features by multivariate analysis. We also investigated the efficiency of combined analysis of several markers to predict the lymph node status.

Cell adhesion molecules have been examined which involved in cell-cell adhesion, cell-extracellular matrix adhesion and cellular interactions. CD44 glycoproteins, cell surface receptors as adhesion molecules binding to its principal ligand hyaluronan, is known to play a major role in cell-cell adhesion, cell-substrate interaction, lymphocytes recruitement to inflammatory sites, and tumor metastasis $(9,10)$. The standard isoform, CD44s, is expressed in a variety of normal tissues. CD44 isoforms containing variant exon 6 (CD44v6), generated by alternative splicing of at least 12 exons, have been studied most extensively. It has been reported that CD44v6 is correlated with regulating tumor invasion, progression and metastasis in various kinds of malignancies including gastric cancer $(11,12)$. In addition, CD44v6 was significantly correlated with lymph node metastasis in gastric cancer (13-15).

CD54, a member of the immunogloblin superfamily and also called ICAM-1, is a glycoprotein with five immunogloblin- 
like extracellular domains (16). CD54 is expressed by various cells including vascular endothelial cells, fibroblasts, dendritic cells, leukocytes and monocytes. When CD54 binds to its ligands LFA-1 and Mac-1 on the surface of T lymphocytes, it plays an essential role as a signal transmitter of immune response, which mediates tumor cytotoxicity (17). It has been reported that CD54 expression on the surface of tumor cells increases the susceptibility of such tumor cells to lymphocyte-mediated tumor cytotoxity through the CD54/ LFA-1 system $(18,19)$. Maruo et al suggested that ICAM-1 was overexpressed in cancer cells and released as solubleICAM-1, which would promote hematogenous metastasis by suppressing local anticancer immunity (20). By contrast, Yashiro et al reported that decreased CD54 expression on cancer cells was significantly correlated with lymphatic spread, which suggested that decreased CD54 might be associated with decreased cytotoxity of immune cells (21).

$\mathrm{Cdx} 2$ is an intestine-specific caudal-related homeobox transcription factor expressed in the epithelium of the small intestine and colorectum, in which it works for cell proliferation, differentiation, and maintaining intestinal phonotypes (22). Cdx2 expression is not detected in normal gastric mucosa, but ectopically observed in nearly all intestinal metaplasia (23). Recent reports demonstrated that intestinal-type gastric cancer developed from intestinal metaplasia in Cdx2-transgenic mice, suggesting that $\mathrm{Cdx} 2$ might be involved in gastric carcinogenesis $(24,25)$. According to the clinical study, $\mathrm{Cdx} 2$ expression in gastric cancer was corelated with better prognosis $(26,27)$. Furthermore, a significant negative correlation has been shown between $\mathrm{Cdx} 2$ expression and lymph node metastasis (28).

Chemokines which were originally identified in inflammatory pathways stimulating the migration of leucocytes, have been recently reported to induce the migration of tumor cells and their expression was associated with tumor growth, angiogenesis and metastatic potential (29). CXCL5, a member of CXC-type chemokines, functions as a proangiogenic factor and as a powerful chemoattractant for granulocytic immune cells mainly through binding its receptor CXCR2. It has been reported that CXCL5 expression contributes to tumor progression and metastasis (30-32). Park et al demonstrated that CXCL5 overexpression was associated with advanced gastric cancer and high $\mathrm{N}$ stage, suggesting a role for CXCL5 in the progression of gastric cancer, specifically in lymph node metastasis (33).

Cell division is a critical event in tumor progression and numorous molecules involved with this process have been investigated intensely in tumor biology. Cyclins, which control the cell cycle, have been shown to be overexpressed in various kinds of malignancies $(34,35)$. Cyclin B1, an important molecule in the cell cycle transition from G2-to-M phase, regulates cell division and cell arrest by cooperating with cdc2 kinase. Previous reports revealed that Cyclin B1 overexpression was observed in the cytoplasm of many cancers and related to prognosis $(36,37)$. Korenaga et al showed the association between cyclin B1 and lymph node metastasis in human colorectal cancer (38). In gastric cancer, Yasuda et al reported that Cyclin B1 overexpression was closely associated with less aggressive tumor behavior, including nodal metastasis and stage of disease (39).
The extracellular matrix (ECM) provides a structural framework to support cells by mediating cell-cell or cell-ECM interactions. Degradation of ECM components is mostly controlled by proteolytic enzymes called matrix metalloproteinases (MMP). The MMP family, zinc-dependent endopeptidases, consists of at least 25 members (40). MMP-7, also known as matrilysin, has proteolytic activities against a wide range of substrates, including not only proteoglycans, fibronectin and laminin, but also type IV collagen (41). MMP-7 is frequently overexpressed in cancer tissues and is associated with cancer progression, which includes multistep process such as cell growth, apoptosis, invasion, metastasis and angiogenesis $(40,42,43)$. Moreover, MMP-7 expression in gastric cancer is associated with aggressive phenotypes including lymph node metastasis $(44,45)$.

$\mathrm{Nm} 23$ was originally identified as a metastasis suppressor gene (46). It has two isotypes, $\mathrm{nm} 23-\mathrm{H} 1$ and $\mathrm{nm} 23-\mathrm{H} 2$, have been shown to be identical to nucleoside diphosphate kinase (NDPK) A and B. Many reports exhibited that reduced expression of nm23 (or nm23-H1) was correlated with tumor metastasis or poor prognosis (47-49). In contrast, overexpression of $\mathrm{nm} 23$ is related to advanced tumors $(50,51)$, suggesting that the significance of nm23 expression is different depending on cancer types. As for gastric cancer, several researchers reported that reduced nm23 expression was related to lymph node metastasis or poor prognosis $(52,53)$. On the other hand, some studies showed opposite results or no significant findings $(54,55)$.

The tumor-associated antigen, receptor-binding cancer antigen expressed on SiSo cells (RCAS1), is recognized by the mouse monoclonal antibody, 22-1-1, which was isolated from mice immunized with the human uterine cervical adenocarcinoma cell line SiSo (56). RCAS1 is a type II membrane protein and expressed on several kinds of carcinomas $(57,58)$. In vitro studies of RCAS1 indicated that it might act as an apoptosis-inducing factor, since RCAS1 induced apoptosis in its receptor expressing cells, such as T, $\mathrm{B}$ and NK cells (56). Thus, RCAS1 is considered to play a role in evasion of immune surveillance. RCAS1 expression in gastric cancer cells was classified as polarity pattern or diffuse pattern (59). The diffuse pattern of gastric cancers was implicated in large size, depth of invasion and regional lymph node metastasis, compared with polarity pattern. Moreover, RCAS1 expression in T3 gastric carcinoma was significantly correlated with the histological type and lymph node metastasis $(60)$.

Survivin, a unique member of the inhibitor of apoptosis protein (IAP) family, is a multifunctional protein that inhibits apoptosis, regulates cell division and enhances angiogenesis (61). In many types of cancers, survivin expression is correlated with reduced apoptosis and unfavorable prognosis (62). Miyachi et al demonstrated that survivin mRNA expression was significantly higher in patients with lymph node metastasis in gastric cancer (63). Lee et al reported that survivin was significantly associated with depth of invasion, tumor stage, poor survival and lymph node metastasis (64). However, there are still conflicting results about survivin expression on gastric cancer (65-67). In the present study, we evaluated the usefulness of these molecules to predict lymph node metastasis in gastric cancer. 


\section{Materials and methods}

Clinical materials. Primary gastric adenocarcinoma specimens were obtained from 135 patients who underwent radical resection at Fukushima Medical University between January 1991 and December 2004. No patients received chemotherapy or radiotherapy before surgery. Among the 135 patients, 91 were male and 44 female. Ages ranged between 31 and 87 years with the mean age of 63.4 years. All patients were treated by lymph node dissection of D1 or D2 according to the Japanese Classification of Gastric Cancer (JSGC), which were defined by location of lymph node relative to the primary site. The resected and examined lymph nodes were at least 15 for each case. The mean number of examined lymph nodes was 27.56 (15-60) and the mean number of metastatic nodes was 3.62 (0-32). No lymph node metastasis was found in $61(45.2 \%)$ cases, whereas, lymph node involvement were present in 74 (54.8\%). Consequently, patients with distant metastases, peritoneal dissemination or extension to other organs (SI) were excluded from the analysis. Patients with only mucosal infiltration (M) were also excluded. Histological type was devided into differentiated and undifferentiated type. Well- and moderately differentiated tubular or papillary adenocarcinomas were classified as differentiated type, and poorly differentiated adenocarcinomas and signet-ring cell carcinomas were classified undifferentiated type. Mucinous adenocarcinomas were classified as either type depending upon the other predominant elements. Of the 135 patients, tubular adenocarcinoma, papillary adenocarcinoma, poorly differentiated adenocarcinoma, signet-ring cell carcinoma and mucinous carcinoma were present in $60,6,55,10$ and 4 patients, respectively. Sixty-five $(48.1 \%)$ were classified as differentiated, $70(51.9 \%)$ were undifferentiated. Depth of tumor invasion was recorded using $\mathrm{T}$ classification, tumor invasion of mucosa (M) or submucosa (SM) was defined as T1, that of muscularis propria (MP) or subserosa (SS) was T2, tumor penetration of serosa (SE) was T3, tumor invasion of adjacent structures (SI) was T4. As for the depth of invasion, 43 cases were T1, 54 were T2 and 38 were T3. Sixty-two cases were allocated to stage I, 28 to stage II, 45 to stage III. The extent of lymphatic (ly) and venous (v) invasion was divided into present or absent. Those clinicopathological findings were determined according to the Japanese Classification of Gastric Cancer (JCGC) (68). Table I shows the clinicopathological features of patients with or without lymph node metastasis. There was no significant difference between the lymph node metastasis and gender, age and histological type. In contrast, the depth of invasion $(\mathrm{p}<0.001)$, lymphatic invasion $(p=0.003)$ and venous invasion $(p<0.001)$ showed significant association with the presence of lymph node involvement.

Immunohistochemistry. All specimens were fixed in formalin and embedded in paraffin. Ten serial sections $(4-\mu \mathrm{m})$ were prepared and one of them was used for hematoxylin and eosin (H\&E) staining, while the others were used for immunohistochemistry. Sections were deparaffinized in xylene and hydrated through a graded series of ethanol. After the sections were rinsed three times in phosphate-buffered
Table I. Clinicopathological features.

\begin{tabular}{|c|c|c|c|c|}
\hline & \multirow[b]{2}{*}{$\begin{array}{c}\text { Total } \\
n=135\end{array}$} & \multicolumn{2}{|c|}{ LN metastasis } & \multirow[b]{2}{*}{ P-value } \\
\hline & & $\begin{array}{c}\text { Positive } \\
n=74\end{array}$ & $\begin{array}{c}\text { Negative } \\
n=61\end{array}$ & \\
\hline Age & & & & 0.295 \\
\hline$>65$ & 73 & 37 & 36 & \\
\hline$\leq 65$ & 62 & 37 & 25 & \\
\hline Gender & & & & 0.965 \\
\hline Male & 91 & 50 & 41 & \\
\hline Female & 44 & 24 & 20 & \\
\hline Histological type & & & & 0.051 \\
\hline Differentiated & 65 & 30 & 35 & \\
\hline Undifferentiated & 70 & 44 & 26 & \\
\hline Depth of invasion & & & & $<0.001$ \\
\hline $\mathrm{T} 1$ & 43 & 11 & 32 & \\
\hline $\mathrm{T} 2$ & 54 & 31 & 23 & \\
\hline $\mathrm{T} 3$ & 38 & 32 & 6 & \\
\hline Lymphatic invasion & & & & 0.003 \\
\hline Present & 25 & 7 & 18 & \\
\hline Absent & 110 & 67 & 43 & \\
\hline Venous invasion & & & & $<0.001$ \\
\hline Present & 39 & 11 & 28 & \\
\hline Absent & 96 & 63 & 33 & \\
\hline
\end{tabular}

saline (PBS), endogenous peroxidase was blocked with $0.3 \%$ $\mathrm{H}_{2} \mathrm{O}_{2}$ in methanol for $30 \mathrm{~min}$. Antigens were retrieved by autoclaving sections on slides in $0.01 \mathrm{M} \mathrm{pH} 6.0$ citrate buffer for $10 \mathrm{~min}$ (except for $\mathrm{nm} 23$ and $\mathrm{Cdx} 2$ ). After being rinsed in PBS, the sections were incubated with each primary antibody overnight at $4^{\circ} \mathrm{C}$. The primary antibodies were anti-CD44v6 (clone 2F10; R\&D Systems, Minneapolis, MN, USA, 1:100), anti-CD54 (clone 23G12; Novocastra, Newcastle, UK, 1:100), anti-Cdx2 (clone CDX2-88; Biogenex, San Ramon, CA, USA, ready for use), anti-CXCL5 (clone 33160; R\&D Systems, 1:50), anti-Cyclin B1 (clone 7A9; Novocastra, 1:50), anti-MMP7 (clone 141-7B2; Daiichi Fine Chemical, Toyama, Japan, 1:200), anti-nm23 (clone 37.6; Novocastra, 1:500), anti-RCAS1 (clone 22-1-1; Medical \& Biological Laboratories, Nagoya, Japan, ready for use), and antiSurvivin (Rabbit polyclonal; Novus Biologicals, Littleton, CO, USA, 1:1000). A further wash in PBS was followed by treatment with peroxidase-labeled polymer conjugated to gout anti-mouse or anti-rabbit immunogloblins (Envison+kit; Dako, Glostrup, Denmark) as the secondary antibody for $30 \mathrm{~min}$ at room temprature. The staining was visualized with diaminobenzidine (DAB), followed by counterstaining with hematoxylin.

Assessment of staining. Sections were considered positive for CD44v6, CD54, CXCL5, Cyclin B1, MMP-7, RCAS1, when more than $5 \%$ of tumor cells were stained in the cytoplasm or 

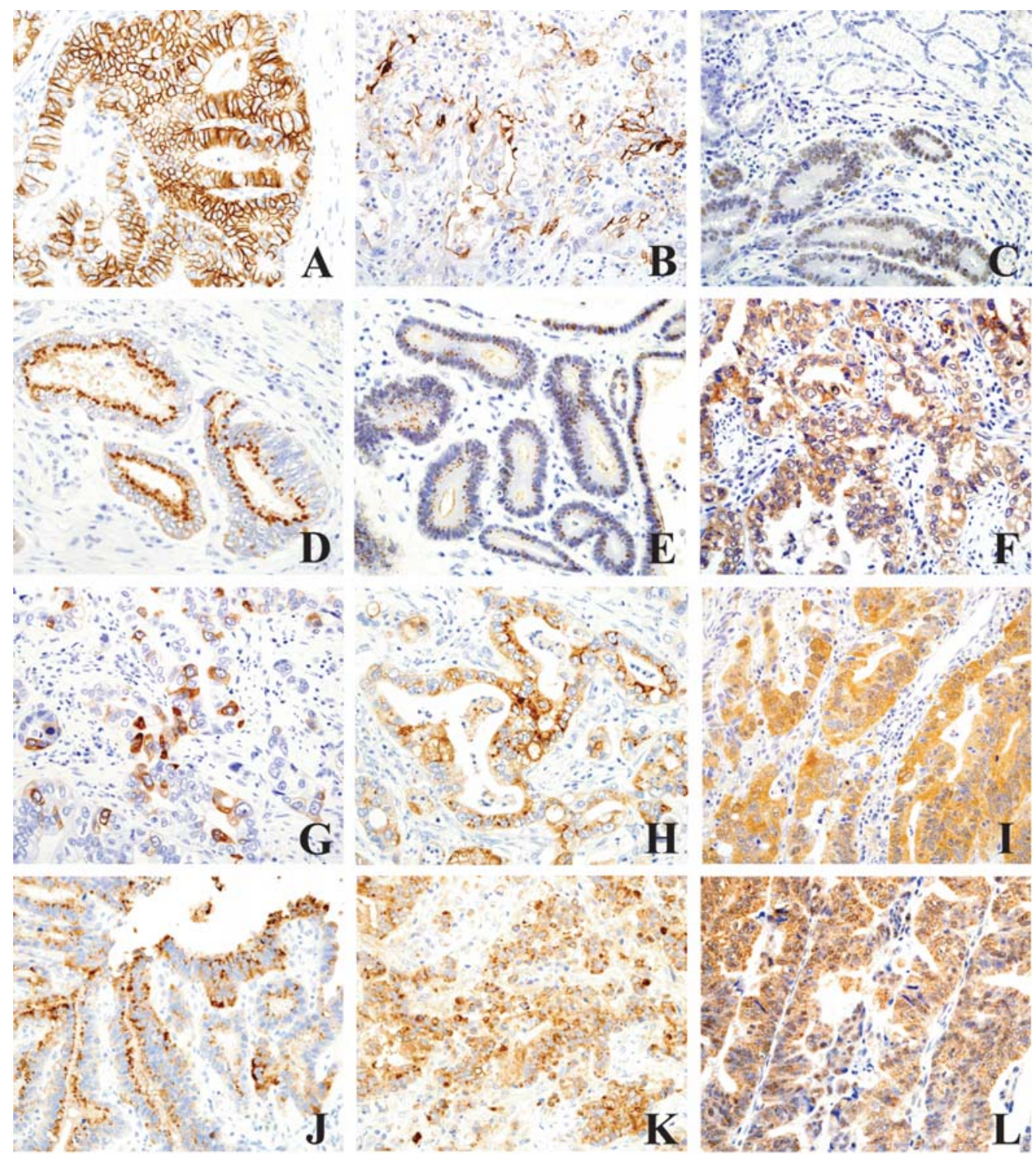

Figure 1. Representative images of immunohistochemical staining for CD44v6, CD54, Cdx2, CXCL5, Cyclin B1, MMP-7, nm23, RCAS1 and Survivin in gastric cancer (original magnification, $\mathrm{x} 40$ ). (A) CD44v6 expressed prominently in membrane of cancer cells. (B) Strong membranous staining of CD54. (C) expression of $\mathrm{Cdx} 2$ in nuclei of tumor cells but absent in normal gastric mucosa adjacent to cancer tissue. (D) Cdx2 granular staining detected in cytoplasm. (E) Both nuclear and cytoplasmic staining of Cdx2. (F) CXCL5 positive expression in cytoplasm. (G) Cyclin B1 expressed heterogeneously in the cytoplasm. (H) MMP-7 stained in the cytoplasm of cancer cells at the invasive part of the tumor. (I) nm23 observed diffusely in cytoplasm and nuclei of tumor cells. (J) RCAS1 defined as P pattern. (K) RCAS1 defined as D pattern. (L) Survivin expression, strong staining in nuclei and diffuse granular staining in cytoplasm of cancer cells.

cell membrane. The expression of $\mathrm{Cdx} 2$ was evaluated cytoplasmic and nuclear staining respectively, and sections with $>5 \%$ stained tumor cells were considered positive. For the expression of nm23, the cases with $>30 \%$ tumor cells in a section were regarded as positive. To quantitate survivin expression, a scoring method was used as described previously $(64,66)$. Staining intensity and percentage of staining area were classified and calculated, sections were then categorized as high expression or low expression. In addition to the evaluation mentioned above, RCAS1 expression was classified into two patterns as described previously (59). Granular staining enriched in the grandular side of cytoplasm with polarity was defined as a P pattern, and granular staining scattered diffusely in the cytoplasm and on the cell membrane was defined D pattern. Assessment of the staining for these molecules was evaluated by two independent investigators (H.O. and K.K.) without knowledge of the clinicopathological data and clinical outcomes of the patients.

Statistical analysis. Associations between categorical variables were evaluated with $\chi^{2}$ test, Fisher's exact test or Mann-Whitney $U$ test. The factors found to be significant in univariate analysis were included in subsequent stepwise multivariate logistic regeression analysis to identify the independent predictors for the lymph node metastasis. Differences at $\mathrm{p}<0.05$ were considered significant. All statistical analyses were performed using SPSS 11.0 software (SPSS Inc., Chicago, IL). 


\section{Results}

Features of expression and relation to clinicopathological factors. In the normal gastric tissue surrounding the cancerous lesions, few normal epithelial cells stained weakly for CD44v6. Among the 135 of primary gastric cancer examined, $84(62.2 \%)$ cases showed positive expression for CD44v6. The staining pattern was intense mainly on the cell membrane and cytoplasm of cancer cells (Fig. 1A). The distribution of CD44v6-expressed cells were found particularly at the invasive region of tumor. As shown in Table II, positive expression of CD44v6 was significantly more frequent when lymph node metastasis $(\mathrm{p}=0.001)$ or lymphatic invasion ( $\mathrm{p}=0.037)$ were present. CD44v6 expression was observed in $55(74.3 \%)$ of 74 cases with lymph node metastasis and $73(66.4 \%)$ of 110 cases with lymphatic invasion. Also as the depth of invasion or stage increased, positive expression rate of CD44v6 became significantly higher ( $p=0.036,0.010$, respectively). No significant correlations could be determined between CD44v6 and other variables such as age, gender, histological type and venous invasion.

CD54 was commonly observed in the vascular endothelial cells and monocytes, but not in the normal gastric epithelial cells. The expression of CD54 was found predominantly in membrane of gastric cancer cells, and also detected in the cytoplasm (Fig. 1B). Fifty one cases (37.8\%) were determined as positive for CD54. CD54 positive expression was correlated with increased depth of invasion $(\mathrm{p}=0.007)$, advanced stage $(p=0.033)$ or presence of venous invasion $(p=0.008)$. No relationship was found between CD54 expression and age, gender, histological type, lymphatic invasion and lymph node status.

Cdx2 was expressed in the nuclei or cytoplasm of tumor cells (Fig. 1C-E). No staining was observed in normal epithelial cells. Nuclear Cdx2 expression was found in 55 cases (40.7\%), whereas cytoplasmic expression was found in 69 cases $(51.1 \%)$. Twenty-five cases $(18.5 \%)$ showed positive expression of both nucleus and cytoplasm. The positive expression of nuclear $\mathrm{Cdx} 2$ was significantly higher in males than in females $(p=0.001)$ and in differentiated types than in undifferentiated types $(\mathrm{p}=0.003)$. There was a significant inverse correlation between nuclear $\mathrm{Cdx} 2$ and depth of invasion $(\mathrm{p}=0.001)$ or stage $(\mathrm{p}<0.001)$, respectively. Furthermore, significantly less expression was observed in cases with lymph node involvement than in those without lymph node involvement $(\mathrm{p}<0.001)$ and in presence of venous invasion than absence of venous invasion $(\mathrm{p}=0.018)$. Nuclear Cdx2 was positive in $20(27.0 \%)$ of 74 cases with lymph node metastasis, and in 35 (57.4\%) of 61 cases without lymph node metastasis. By contrast, cytoplasmic expression of $\mathrm{Cdx} 2$ was only related to histological type $(\mathrm{p}=0.032)$ and gender $(\mathrm{p}=0.006)$.

CXCL5 expression existed focally in the cytoplasm of normal gastric epithelial cells and gastric cancer cells (Fig. 1F). Seventy-three cases $(54.1 \%)$ were defined positive for CXCL5. The expression of CXCL5 positive rate was related to advanced depth of invasion $(\mathrm{p}=0.029)$ or advanced stage $(\mathrm{p}=0.008)$, respectively. However, correlations with any of these clinicopathological variables were not observed.
Weak and focal expression of Cyclin B1 was detected in the cytoplasm of normal gastric epithelial cells. In gastric cancer, Cyclin B1 was observed more intense predominantly in the cytoplasm of tumor cells (Fig. 1G). The positive expression of Cyclin B1 was found in 56 cases (41.5\%). No significant association was observed between Cyclin B1 expression and clinicopathologic features, except for histological type $(\mathrm{p}=0.002)$.

The expression of MMP-7 was hardly detected in normal gastric mucosa. In gastric cancer, MMP-7 was expressed in cytoplasm and membrane of cancer cells (Fig. 1H). Stained cells were found heterogeneously in cancerous tissue, especially in invasive region of the tumor. MMP-7 positive cases were detected in $96(71.1 \%)$ of 135 cases. MMP-7 positive expression was significantly correlated with presence of lymph node metastasis $(\mathrm{p}<0.001)$, depth of invasion $(\mathrm{p}<0.001)$ and stage $(\mathrm{p}<0.001)$. Sixty-two $(83.8 \%)$ of 74 cases with lymph node metastasis showed positive for MMP-7. On the other hand, MMP-7 expression was not significantly associated with other variables, including gender, histological type, lymphatic or venous invasion.

Almost all normal gastric epithelial cells were stained homogeneously for nm23. In gastric cancer, nm23 was found in cytoplasm and nuclei of cancer cells that were more intense than normal tissue (Fig. 1I). The majority of cancer specimens were stained diffusely, 113 cases $(83.7 \%)$ were in fact determined as positive for $n m 23$. Among 22 cases of nm23 negative group, 20 cases $(90.9 \%)$ were undifferentiated type. In addition, in ten signet-ring cell carcinoma cases, eight $(80.0 \%)$ were markedly negative for $n m 23$. The negative expression of nm23 was significantly correlated with younger age $(p=0.022)$, undifferentiated histological type $(p<0.001)$ and increased stage $(p=0.046)$, but not with other parameters including lymph node metastasis.

RCAS1 expression was present in both cytoplasm and membrane of normal epithelial cells and cancer cells. All 135 gastric cancer specimens showed positive expression of RCAS1. Therefore, tumors were further categorized to $P$ pattern or D pattern as previously described (59) (Fig. 1J and $\mathrm{K})$. Of 135 cases, $62(45.9 \%)$ and $73(54.1 \%)$ were defined as $\mathrm{P}$ pattern and D pattern, respectively. There was a significant difference between RCAS1 expression pattern and several clinicopathological parameters such as histological type $(\mathrm{p}=0.005)$, depth of invasion $(\mathrm{p}<0.001)$, venous invasion $(\mathrm{p}=0.002)$, lymph node metastasis $(\mathrm{p}=0.006)$ and stage $(\mathrm{p}<0.001)$. D pattern of RCAS1 expression were associated with undifferentiated histological type, incidence of venous invasion, presence of lymph node metastasis, increased depth of invasion and advanced clinical stage. Forty-eight (65.8\%) of 73 cases defined as D pattern had lymph node involvement.

The expression of survivin was observed primarily in the nuclei but was also weakly present in the cytoplasm. Survivin was detected strongly in gastric cancer cells, while weak staining was diffusely detected in normal epithelial cells (Fig. 1L). High expression of survivin was more frequently observed in males than in females $(\mathrm{p}=0.009)$, and in differentiated type $(\mathrm{p}=0.001)$ than in unddifferentiated type. No significant association was detected between survivin expression and any other variables. 
Table II. Correlation between markers and clinicopathological features.

\begin{tabular}{|c|c|c|c|c|c|c|c|c|c|c|}
\hline & \multicolumn{2}{|c|}{ CD44v6 } & \multicolumn{2}{|c|}{ CD54 } & \multicolumn{2}{|c|}{ Cdx 2 cytoplasmic } & \multicolumn{2}{|c|}{ Cdx2 nuclear } & \multicolumn{2}{|c|}{ CXCL5 } \\
\hline & $\begin{array}{c}\text { Positive } \\
n=84\end{array}$ & $\begin{array}{c}\text { Negative } \\
n=51\end{array}$ & $\begin{array}{c}\text { Positive } \\
n=51\end{array}$ & $\begin{array}{c}\text { Negative } \\
n=84\end{array}$ & $\begin{array}{c}\text { Positive } \\
n=69\end{array}$ & $\begin{array}{c}\text { Negative } \\
n=66\end{array}$ & $\begin{array}{c}\text { Positive } \\
n=55\end{array}$ & $\begin{array}{c}\text { Negative } \\
n=80\end{array}$ & $\begin{array}{c}\text { Positive } \\
n=73\end{array}$ & $\begin{array}{c}\text { Negative } \\
n=62\end{array}$ \\
\hline \multicolumn{11}{|l|}{ Age } \\
\hline$>65$ & 45 & 28 & 31 & 42 & 34 & 39 & 30 & 43 & 34 & 39 \\
\hline$\leq 65$ & 39 & $\begin{array}{c}23 \\
\mathrm{p}=0.880\end{array}$ & 20 & $\begin{array}{c}42 \\
p=0.223\end{array}$ & 35 & $\begin{array}{c}27 \\
\mathrm{p}=0.253\end{array}$ & 25 & $\begin{array}{c}37 \\
\mathrm{p}=0.927\end{array}$ & 39 & $\begin{array}{c}23 \\
\mathrm{p}=0.058\end{array}$ \\
\hline
\end{tabular}

Gender

Male

Female

Histological type

Differentiated

Undifferentiated

38
46

$\begin{array}{cr}27 & 23 \\ 24 & 28 \\ \mathrm{p}= & 0.385\end{array}$

42

42

$\mathrm{p}=0.580$
46

28
33

18

$\mathrm{p}=0.602$

$$
39
$$

52

14

$\mathrm{p}=0.006$

46
9

9

45
35
$\mathrm{p}=0.001$

44

29

29

47

15

$\mathrm{p}=0.055$

Depth of invasion

$\begin{array}{cccccccccccc}\mathrm{T} 1 & 21 & 22 & 10 & 33 & 17 & 26 & 22 & 21 & 16 & 27 \\ \mathrm{~T} 2 & 36 & 18 & 21 & 33 & 32 & 22 & 28 & 26 & 34 & 20 \\ \mathrm{~T} 3 & 27 & 11 & 20 & 18 & 20 & 18 & 5 & 33 & 23 & 15 \\ & & \mathrm{p}=0.036 & & \mathrm{p}=0.007 & & \mathrm{p}=0.209 & & \mathrm{p}=0.001 & \mathrm{p}=0.029\end{array}$

Lymphatic invasion

Present

Absent

$\begin{array}{cc}37 & 44 \\ 14 & 7 \\ \mathrm{p}=0.037\end{array}$

$\begin{array}{cr}66 & 58 \\ 18 & 11 \\ \mathrm{p}=0.264\end{array}$

$\begin{array}{cc}52 & 44 \\ 44 & 11 \\ \mathrm{p}=0.431\end{array}$

66
14
$p=0.713$

$\begin{array}{cc}62 & 48 \\ 11 & 14 \\ & \mathrm{p}=0.263\end{array}$

Venous invasion

$$
\text { Present }
$$

Absent

$\begin{array}{cc}62 & 34 \\ 22 & 17 \\ & \mathrm{p}=0.375\end{array}$

43
8

$\begin{array}{cc}53 & 48 \\ 31 & 21 \\ \mathrm{p}=0.008\end{array}$

48
18
$\mathrm{p}=0.685$

$\begin{array}{cccc}33 & 63 & 53 & 43 \\ 22 & 17 & 20 & 19 \\ & \mathrm{p}=0.018 & & \mathrm{p}=0.678\end{array}$

LN metastasis

$\begin{array}{lcccccccccc}\text { Positive } & 55 & 19 & 32 & 42 & 38 & 36 & 20 & 54 & 45 & 29 \\ \text { Negative } & 29 & 32 & 19 & 42 & 31 & 30 & 35 & 26 & 28 & 33 \\ & & \mathrm{p}=0.001 & & \mathrm{p}=0.149 & & \mathrm{p}=0.951 & & \mathrm{p}<0.001 & \mathrm{p}=0.084\end{array}$

\section{Stage}

\begin{tabular}{lccccccccccc} 
I & 31 & 31 & 17 & 45 & 27 & 35 & 38 & 24 & 25 & 37 \\
II & 20 & 8 & 13 & 15 & 17 & 11 & 9 & 19 & 19 & 9 \\
III & 33 & 12 & 21 & 24 & 25 & 20 & 8 & 37 & 29 & 16 \\
& & $\mathrm{p}=0.010$ & & $\mathrm{p}=0.033$ & & $\mathrm{p}=0.177$ & & $\mathrm{p}<0.001$ & $\mathrm{p}=0.008$ \\
\hline
\end{tabular}


Table II. Continued.

\begin{tabular}{|c|c|c|c|c|c|c|c|c|c|c|}
\hline & \multicolumn{2}{|c|}{ Cyclin B1 } & \multicolumn{2}{|c|}{ MMP7 } & \multicolumn{2}{|c|}{$\mathrm{nm} 23$} & \multicolumn{2}{|c|}{ RCASI } & \multicolumn{2}{|c|}{ Survivin } \\
\hline & $\begin{array}{c}\text { Positive } \\
n=56\end{array}$ & $\begin{array}{c}\text { Negative } \\
n=79\end{array}$ & $\begin{array}{c}\text { Positive } \\
\text { n=96 }\end{array}$ & $\begin{array}{c}\text { Negative } \\
n=39\end{array}$ & $\begin{array}{c}\text { Positive } \\
n=113\end{array}$ & $\begin{array}{c}\text { Negative } \\
n=22\end{array}$ & $\begin{array}{c}P \\
n=62\end{array}$ & $\begin{array}{c}D \\
n=73\end{array}$ & $\begin{array}{l}\text { High } \\
n=99\end{array}$ & $\begin{array}{l}\text { Low } \\
n=36\end{array}$ \\
\hline \multicolumn{11}{|l|}{ Age } \\
\hline$>65$ & 32 & 41 & 46 & 27 & 66 & 7 & 29 & 44 & 55 & 18 \\
\hline$\leq 65$ & 74 & $\begin{array}{c}38 \\
\mathrm{p}=0.547\end{array}$ & 50 & $\begin{array}{c}12 \\
\mathrm{p}=0.024\end{array}$ & 47 & $\begin{array}{c}15 \\
\mathrm{p}=0.022\end{array}$ & 33 & $\begin{array}{c}29 \\
p=0.117\end{array}$ & 44 & $\begin{array}{c}18 \\
p=0.567\end{array}$ \\
\hline
\end{tabular}

Gender

Male

Female

41

15

29

$\mathrm{p}=0.226$

36

29

Differentiated

Undifferentiated

20

50
$\mathrm{p}=0.002$

42
54

23

$16 \quad 50$

2
20
$p=0.001$

$\mathrm{p}=0.109$

$\mathrm{p}=0.001$

Depth of invasion

T1

T2

T3

$\begin{array}{ccc}15 & 28 & 23 \\ 30 & 24 & 39 \\ 11 & 27 & 34 \\ & \mathrm{p}=0.698 & \end{array}$

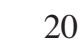$$
20
$$

15

4

$\mathrm{p}=0.001$

37
45
31

6
9
7
$=0.585$

29

27

14
27
32
$\mathrm{p}=0.001$

$\begin{array}{cc}35 & 8 \\ 38 & 16 \\ 26 & 12 \\ & \mathrm{p}=0.178\end{array}$

Lymphatic invasion

Present
Absent

49

$\begin{array}{cr}61 & 82 \\ 18 & 14 \\ \mathrm{p}=0.130 & \end{array}$

$\begin{array}{cr}28 & 93 \\ 11 & 20 \\ \mathrm{p}=0.065 & \end{array}$

17
5
$\mathrm{p}=$

49
13

61
12
$\mathrm{p}=0.500$

$\begin{array}{cc}78 & 32 \\ 21 & 4 \\ & \mathrm{p}=0.182\end{array}$

Venous invasion

$$
\text { Present }
$$

Absent

$\begin{array}{cc}42 & 54 \\ 14 & 25 \\ & \mathrm{p}=0.401\end{array}$

$\begin{array}{ccc}72 & 24 & 79 \\ 24 & 15 & 34 \\ & \mathrm{p}=0.118 & \end{array}$

17
5
$\mathrm{p}=0.486$

36
26

60
13
$p=0.002$

$\begin{array}{cc}69 & 27 \\ 30 & 9 \\ & \mathrm{p}=0.548\end{array}$

LN metastasis

$\begin{array}{lcccccccccr}\text { Positive } & 35 & 39 & 62 & 12 & 59 & 15 & 26 & 48 & 53 & 21 \\ \text { Negative } & 21 & 40 & 34 & 27 & 54 & 7 & 36 & 25 & 46 & 15 \\ & & \mathrm{p}=0.131 & & \mathrm{p}=0.001 & & \mathrm{p}=0.169 & & \mathrm{p}<0.006 & \mathrm{p}=0.620\end{array}$

Stage

\begin{tabular}{lccccccccccc} 
I & 23 & 39 & 32 & 28 & 55 & 7 & 38 & 24 & 48 & 14 \\
II & 16 & 12 & 21 & 7 & 25 & 3 & 15 & 13 & 23 & 5 \\
III & 17 & 28 & 41 & 4 & 33 & 12 & 9 & 36 & 28 & 17 \\
& & $\mathrm{p}=0.767$ & & $\mathrm{p}=0.001$ & & $\mathrm{p}=0.046$ & & $\mathrm{p}<0.001$ & $\mathrm{p}=0.111$ \\
\hline
\end{tabular}


Table III. Univariate and multivariate logistic regression analysis with respect to lymph node metastasis.

\begin{tabular}{|c|c|c|c|c|c|c|c|}
\hline & & \multicolumn{3}{|c|}{ Univariate } & \multicolumn{3}{|c|}{ Multivariate } \\
\hline & & Odds ratio & $95 \% \mathrm{CI}$ & P-value & Odds ratio & $95 \% \mathrm{CI}$ & P-value \\
\hline Age & $\leq 65$ vs. $>65$ & 0.694 & $0.350-1.376$ & 0.296 & & & \\
\hline Gender & Male vs. Female & 1.016 & $0.493-2.064$ & 0.965 & & & \\
\hline Histological type & $\begin{array}{l}\text { Differentiated vs. } \\
\text { Undifferentiated }\end{array}$ & 1.974 & $0.993-3.927$ & 0.053 & & & NS \\
\hline Depth of invasion & T1 vs. T2/T3 & 6.320 & $2.800-14.264$ & $<0.001$ & 4.524 & $1.876-10.911$ & 0.001 \\
\hline Lymphatic invasion & Absent vs. Present & 4.007 & $1.544-10.395$ & 0.004 & & & NS \\
\hline Venous invasion & Absent vs. Present & 4.860 & $2.152-10.976$ & $<0.001$ & & & NS \\
\hline CD44v6 & Negative vs. Positive & 3.194 & $1.548-6.590$ & 0.002 & 2.390 & $1.036-5.512$ & 0.041 \\
\hline CD54 & Negative vs. Positive & 1.684 & $0.827-3.428$ & 0.151 & & & \\
\hline cytoplasmic $\mathrm{Cdx} 2$ & Negative vs. Positive & 1.022 & $0.519-2.012$ & 0.951 & & & \\
\hline nuclear $\mathrm{Cdx} 2$ & Negative vs. Positive & 0.275 & $0.134-0.566$ & $<0.001$ & 0.284 & $0.125-0.641$ & 0.002 \\
\hline CXCL5 & Negative vs. Positive & 1.829 & $0.920-3.634$ & 0.085 & & & \\
\hline Cyclin B1 & Negative vs. Positive & 1.709 & $0.851-3.435$ & 0.132 & & & \\
\hline MMP-7 & Negative vs. Positive & 4.103 & $1.847-9.116$ & 0.001 & 2.667 & $1.075-6.612$ & 0.034 \\
\hline $\mathrm{nm} 23$ & Negative vs. Positive & 0.510 & $0.193-1.345$ & 0.174 & & & \\
\hline RCAS1 & P pattern vs. D pattern & 2.658 & $1.322-5.346$ & 0.006 & & & NS \\
\hline Survivin & Low vs. High & 1.215 & $0.562-2.628$ & 0.621 & & & \\
\hline
\end{tabular}

CI, confidence interval; NS, not significant.

Table IV. Multivariate analysis with respect to lymph node metastasis in submucosal and advanced cancer group.

\begin{tabular}{|c|c|c|c|c|c|c|c|}
\hline & & \multicolumn{3}{|c|}{ Submucosal cancer group $(n=43)$} & \multicolumn{3}{|c|}{ Advanced cancer group (n=92) } \\
\hline & & Odds ratio & $95 \% \mathrm{CI}$ & P-value & Odds ratio & $95 \% \mathrm{CI}$ & P-value \\
\hline Histological type & $\begin{array}{l}\text { Differentiated vs. } \\
\text { Undifferentiated }\end{array}$ & & & NS & & & NS \\
\hline Depth of invasion & T1 vs. T2/T3 & & & NS & & & NS \\
\hline Lymphatic invasion & Absent vs. Present & & & NS & & & NS \\
\hline Venous invasion & Absent vs. Present & & & NS & 9.090 & $2.065-40.018$ & 0.004 \\
\hline CD44v6 & Negative vs. Positive & 7.500 & $1.382-40.689$ & 0.020 & & & NS \\
\hline nuclear Cdx2 & Negative vs. Positive & & & NS & 0.323 & $0.115-0.908$ & 0.032 \\
\hline MMP-7 & Negative vs. Positive & & & NS & 3.785 & $1.164-12.308$ & 0.027 \\
\hline RCAS1 & P pattern vs. $\mathrm{D}$ pattern & & & NS & & & NS \\
\hline
\end{tabular}

CI, confidence interval; NS, not significant.

Multivariate analysis of factors related to lymph node metastasis. As shown in Table III, among factors shown to have a correlation with the presence of lymph node metastasis by univariate analyses, subsequent multivariate analysis using the logistic regression model demonstrated that several conventional clinicopathological factors, including depth of invasion and venous invasion were significant independent predictors for lymph node metastasis. CD44v6 and MMP-7 expression were also found to be independently related to lymph node metastasis. Moreover, expression Cdx2 in nuclei was a significant negative predictor of lymph node metastasis. In the submucosal cancer group, only CD44v6 expression was found to be significantly and independently related to lymph node metastasis. In advanced cancer group, positive MMP-7 and negative nuclear $\mathrm{Cdx} 2$ expression, respectively, were significant predictors for lymph node metastasis (Table IV). To investigate the implications of combined analysis, cases could be categorized into two groups: CD44v6 (+), MMP7 (+), nuclear Cdx2 (-) or others. The former group also proved to be independent indicator of lymph node metastasis (Table V). 
Table V. Multivariate logistic regression analysis with respect to lymph node metastasis.

\begin{tabular}{|c|c|c|c|c|}
\hline & & Odds ratio & $95 \% \mathrm{CI}$ & P-value \\
\hline Histological type & Differentiated vs. Undifferentiated & & & NS \\
\hline Depth of invasion & T1 vs. T2/T3 & 3.169 & $1.265-7.940$ & 0.014 \\
\hline Lymphatic invasion & Absent vs. Present & & & NS \\
\hline Venous invasion & Absent vs. Present & 2.678 & $1.054-6.808$ & 0.038 \\
\hline CD44v6, MMP-7, nuclear Cdx2 & $+/+/$ - vs. others & 3.280 & $1.320-8.149$ & 0.011 \\
\hline
\end{tabular}

CI, confidence interval; NS, not significant.

\section{Discussion}

Lymph node metastasis is known to be one of the most important prognostic factors for gastric cancer. There are several distinct steps in the process of lymphatic metastasis of cancer cells, including tumor lymphangiogenesis, infiltration into lymphatic vessels, shedding and floating in lymphatic vessels, migration, adhesion, and proliferation into lymph nodes. Various kinds of molecular markers have been investigated to find as predictive factors for lymph node status in gastric cancer. Those include oncogenes, tumor suppressor genes, growth factors, adhesion molecules, cytokines, chemokines, proteolytic molecules and angiogenic factors. However, the significance of these markers was not consistent with the results of other studies which showed conflicting results or different outcome. It might be caused by research design, technical procedure, different antibodies and the method for the assessment of staining. In the present study, we selected nine molecules from many previous reports as candidate predictors for lymph node metastasis and attempted to clarify which could be the most useful clinically.

The expression of CD44 splice variants $(\mathrm{CD} 44 \mathrm{v})$ on tumor cells, coupled with evidence that upregulation of CD44v confers metastatic potential in vivo and results in poor prognosis (69-71), has focused attention on CD44v in the biology of various human malignancies. However, the direct role of $\mathrm{CD} 44 \mathrm{v}$ in the metastatic process has remained obscure. It has been reported that CD44v6 in gastric cancer was related to tumor growth and metastasis, especially in lymph node metastasis $(13,14)$. In our study, we demonstrated a significant relationship between CD44v6 expression and lymph node metastasis, lymphatic invasion, depth of invasion and stage by univariate analyses. Multivariate analysis revealed that CD44v6 represents an independent predictor of lymph node metastasis. Additionally, in submucosal carcinoma group, CD44v6 might be the only indicator of lymph node metastasis.

MMP-7 overexpression has been identified generally in a variety of malignant tumors. There is substantial evidence that overexpression of MMP-7 correlates with a more aggressive phenotype. It was initially believed that MMP-7 expressing tumors could proteolytically break down the physical barriers, through degradation of ECM components, thereby initiating tumor invasion, intravasation into vessels, extravasation from the circulation, and local migration at metastatic sites $(72,73)$. Furthermore, recent studies revealed MMP-7 to have multiple biological functions associated with tumor behavior, such as growth, invasion, apoptosis and angiogenesis, by modifying other MMP members and nonECM molecules $(41,73)$. Our results revealed that MMP-7 stained cells were detected in invasive front of the tumor, and MMP-7 positive tumors were found to be significantly correlated with aggressive clinicopathological factors, such as depth of invasion, stage and lymph node metastasis, whereas, no significant relationship was detected in histological type and lymphatic or venous invasion. We further demonstrated that MMP-7 was useful as an independent predictor of lymph node metastasis by multivariate logistic analysis.

Previous reports have shown that intestinal metaplasia increases the risk for the development of gastric cancer, therefore intestinal metaplasia is an important precancerous lesion in the multistep gastric carcinogenesis (74). $\mathrm{Cdx} 2$ is an intestine-specific transcription factor expressed in the epithelium from the duodenum to the distal colon, but not in normal gastric mucosa. As shown in the present study, we investigated the expression of $\mathrm{Cdx} 2$ in both nuclei and cytoplasm of tumor cells, 55 cases $(40.7 \%)$ and 69 cases $(51.1 \%)$ in 135 gastric cancers, respectively, were found to be positive expression. We showed that negative expression of nuclear Cdx2 was significantly associated with variables suggesting aggressive phenotypes such as undifferentiated type, advanced $\mathrm{T}$ stage, increased stage and incidence of lymph node metastasis, by univariate analyses. In contrast, cytoplasmic $\mathrm{Cdx} 2$ might not be useful as an indicator of clinicopathological parameters. Multivariate analysis showed that nuclear $\mathrm{Cdx} 2$ expression was a significant independent indicator of lymph node status. Our results are consistent with previous studies which suggest that $\mathrm{Cdx} 2$ may play a suppressive role in progression and carcinogenesis of gastric carcinoma $(28,75)$.

Given that three indicators, including CD44v6, MMP-7 and nuclear $\mathrm{Cdx} 2$, were independent predictive factors for lymph node involvement, we further analyzed the significance of combined expression of these markers. Multivariate analysis revealed that combined CD44v6 (+)/MMP-7 (+)/ nuclear Cdx2 (-) cases were significantly correlated with lymph node metastasis.

Unlike the three molecules mentioned above, regarding other markers, the expression of CD54 and CXCL5 were significantly correlated with deeper depth of invasion and advanced stage of tumor, but not with lymph node status. Likewise, Cyclin B1, nm23 and survivin were not related to lymph node metastasis, although they were significantly higher in differentiated type than in undifferentiated type. Therefore, these findings suggest that CD54, CXCL5, Cyclin 
$\mathrm{B} 1, \mathrm{~nm} 23$ and survivin might be involved in tumor proliferation or differentiation, whereas not be useful in predicting lymphatic metastasis. On the other hand, RCAS1 was detected in all tumor specimens, and the expression pattern of RCAS1 was found to be related to several clinicopathological variables, including histological type, depth of invasion, venous invasion, stage of tumor and lymph node status. However, multivariate analysis showed that RCAS1 could not independently predict lymph node involvement.

In conclusion, our results provide evidence that positive expression of both CD44v6 and MMP-7, and negative expression of nuclear $\mathrm{Cdx} 2$ may serve as powerful indicators for predicting lymph node metastasis in gastric cancer. In addition, combined evaluation of these markers can be clinically useful to predict lymph node metastasis in patients with gastric cancer. This may be helpful to determine the appropriate treatment of gastric cancer.

\section{References}

1. Parkin DM, Bray F, Ferlay $\mathrm{J}$ and Pisani P: Global cancer statistics, 2002. CA Cancer J Clin 55: 74-108, 2005.

2. Yokota T, Ishiyama S, Saito T, Teshima S, Narushima Y, Murata K, Iwamoto K, Yashima R, Yamauchi H and Kikuchi S: Lymph node metastasis as a significant prognostic factor in gastric cancer: a multiple logistic regression analysis. Scand J Gastroenterol 39: 380-384, 2004.

3. Kim JP, Hur YS and Yang HK: Lymph node metastasis as a significant prognostic factor in early gastric cancer: analysis of 1,136 early gastric cancers. Ann Surg Oncol 2: 308-313, 1995.

4. Dicken BJ, Bigam DL, Cass C, Mackey JR, Joy AA and Hamilton SM: Gastric adenocarcinoma: review and considerations for future directions. Ann Surg 241: 27-39, 2005.

5. Jansen EP, Boot H, Verheij M and van de Velde CJ: Optimal locoregional treatment in gastric cancer. J Clin Oncol 23: 4509-4517, 2005.

6. McCulloch P, Niita ME, Kazi H and Gama-Rodrigues JJ: Gastrectomy with extended lymphadenectomy for primary treatment of gastric cancer. Br J Surg 92: 5-13, 2005.

7. Soetikno R, Kaltenbach T, Yeh R and Gotoda T: Endoscopic mucosal resection for early cancers of the upper gastrointestinal tract. J Clin Oncol 23: 4490-4498, 2005.

8. Kim MC, Kim KH, Kim HH and Jung GJ: Comparison of laparoscopy-assisted by conventional open distal gastrectomy and extraperigastric lymph node dissection in early gastric cancer. J Surg Oncol 91: 90-94, 2005.

9. Aruffo A, Stamenkovic I, Melnick M, Underhill CB and Seed B: CD44 is the principal cell surface receptor for hyaluronate. Cell 61: 1303-1313, 1990

10. Hofmann M, Rudy W, Zoller M, Tolg C, Ponta H, Herrlich P and Gunthert U: CD44 splice variants confer metastatic behavior in rats: homologous sequences are expressed in human tumor cell lines. Cancer Res 51: 5292-5297, 1991

11. Muller W, Schneiders A, Heider KH, Meier S, Hommel G and Gabbert HE: Expression and prognostic value of the CD44 splicing variants v5 and v6 in gastric cancer. J Pathol 183: 222-227, 1997.

12. Hong RL, Lee WJ, Shun CT, Chu JS and Chen YC: Expression of CD44 and its clinical implication in diffuse-type and intestinaltype gastric adenocarcinomas. Oncology 52: 334-339, 1995.

13. Kurozumi K, Nishida T, Nakao K, Nakahara M and Tsujimoto M: Expression of CD44 variant 6 and lymphatic invasion: importance to lymph node metastasis in gastric cancer. World J Surg 22: 853-857, 1998.

14. Castella EM, Ariza A, Pellicer I, Fernandez-Vasalo A and Ojanguren I: Differential expression of CD44v6 in metastases of intestinal and diffuse types of gastric carcinoma. J Clin Pathol 51: 134-137, 1998

15. Joo M, Lee HK and Kang YK: Expression of E-cadherin, betacatenin, CD44s and CD44v6 in gastric adenocarcinoma: relationship with lymph node metastasis. Anticancer Res 23: 1581-1588, 2003.
16. Staunton DE, Marlin SD, Stratowa C, Dustin ML and Springer TA: Primary structure of ICAM-1 demonstrates interaction between members of the immunoglobulin and integrin supergene families. Cell 52: 925-933, 1988.

17. Staunton DE, Dustin ML, Erickson HP and Springer TA: The arrangement of the immunoglobulin-like domains of ICAM-1 and the binding sites for LFA-1 and rhinovirus. Cell 61: 243-254, 1990.

18. Vanky F, Wang P, Patarroyo M and Klein E: Expression of the adhesion molecule ICAM-1 and major histocompatibility complex class I antigens on human tumor cells is required for their interaction with autologous lymphocytes in vitro. Cancer Immunol Immunother 31: 19-27, 1990 .

19. Jackson AM, Alexandrov AB, Gribben SC, Esuvarnathan K and James K: Expression and shedding of ICAM-1 in bladder cancer and its immunotherapy. Int J Cancer 55: 921-925, 1993.

20. Maruo Y, Gochi A, Kaihara A, Shimamura H, Yamada T, Tanaka N and Orita K: ICAM-1 expression and the soluble ICAM-1 level for evaluating the metastatic potential of gastric cancer. Int J Cancer 100: 486-490, 2002.

21. Yashiro M, Sunami T and Hirakawa K: CD54 expression is predictive for lymphatic spread in human gastric carcinoma. Dig Dis Sci 50: 2224-2230, 2005.

22. Suh E and Traber PG: An intestine-specific homeobox gene regulates proliferation and differentiation. Mol Cell Biol 16: 619-625, 1996.

23. Eda A, Osawa H, Yanaka I, Satoh K, Mutoh H, Kihira K and Sugano K: Expression of homeobox gene CDX2 precedes that of CDX1 during the progression of intestinal metaplasia. J Gastroenterol 37: 94-100, 2002.

24. Mutoh H, Sakurai S, Satoh K, Tamada K, Kita H, Osawa H, Tomiyama T, Sato Y, Yamamoto H, Isoda N, Yoshida T, Ido K and Sugano K: Development of gastric carcinoma from intestinal metaplasia in Cdx2-transgenic mice. Cancer Res 64: 7740-7747, 2004.

25. Silberg DG, Sullivan J, Kang E, Swain GP, Moffett J, Sund NJ, Sackett SD and Kaestner KH: Cdx2 ectopic expression induces gastric intestinal metaplasia in transgenic mice. Gastroenterology 122: 689-696, 2002.

26. Mizoshita T, Tsukamoto T, Nakanishi H, Inada K, Ogasawara N, Joh T, Itoh M, Yamamura Y and Tatematsu M: Expression of $\mathrm{Cdx} 2$ and the phenotype of advanced gastric cancers: relationship with prognosis. J Cancer Res Clin Oncol 129: 727-734, 2003.

27. Seno H, Oshima M, Taniguchi MA, Usami K, Ishikawa TO, Chiba T and Taketo MM: CDX2 expression in the stomach with intestinal metaplasia and intestinal-type cancer: prognostic implications. Int J Oncol 21: 769-774, 2002.

28. Fan Z, Li J, Dong B and Huang X: Expression of Cdx2 and hepatocyte antigen in gastric carcinoma: correlation with histologic type and implications for prognosis. Clin Cancer Res 11: 6162-6170, 2005

29. Kakinuma T and Hwang ST: Chemokines, chemokine receptors, and cancer metastasis. J Leukoc Biol 79: 639-651, 2006.

30. Miyazaki H, Patel V, Wang H, Edmunds RK, Gutkind JS and Yeudall WA: Down-regulation of CXCL5 inhibits squamous carcinogenesis. Cancer Res 66: 4279-4284, 2006.

31. Begley LA, Kasina S, Mehra R, Adsule S, Admon AJ, Lonigro RJ, Chinnaiyan AM and Macoska JA: CXCL5 promotes prostate cancer progression. Neoplasia 10: 244-254, 2008

32. Speetjens FM, Kuppen PJ, Sandel MH, Menon AG, Burg D, van de Velde CJ, Tollenaar RA, de Bont HJ and Nagelkerke JF: Disrupted expression of CXCL5 in colorectal cancer is associated with rapid tumor formation in rats and poor prognosis in patients. Clin Cancer Res 14: 2276-2284, 2008.

33. Park JY, Park KH, Bang S, Kim MH, Lee JE, Gang J, Koh SS and Song SY: CXCL5 overexpression is associated with late stage gastric cancer. J Cancer Res Clin Oncol 133: 835-840, 2007.

34. Patel V, Jakus J, Harris CM, Ensley JF, Robbins KC and Yeudall WA: Altered expression and activity of G1/S cyclins and cyclin-dependent kinases characterize squamous cell carcinomas of the head and neck. Int J Cancer 73: 551-555, 1997.

35. Nielsen NH, Arnerlov C, Emdin SO and Landberg G: Cyclin E overexpression, a negative prognostic factor in breast cancer with strong correlation to oestrogen receptor status. Br J Cancer 74: 874-880, 1996.

36. Soria JC, Jang SJ, Khuri FR, Hassan K, Liu D, Hong WK and Mao L: Overexpression of cyclin B1 in early-stage non-small cell lung cancer and its clinical implication. Cancer Res 60: 4000-4004, 2000 
37. Wang A, Yoshimi N, Ino N, Tanaka T and Mori H: Overexpression of cyclin B1 in human colorectal cancers. J Cancer Res Clin Oncol 123: 124-127, 1997.

38. Korenaga D, Takesue F, Yasuda M, Honda M, Nozoe T and Inutsuka $\mathrm{S}$ : The relationship between cyclin $\mathrm{B} 1$ overexpression and lymph node metastasis in human colorectal cancer. Surgery 131: S114-S120, 2002.

39. Yasuda M, Takesue F, Inutsuka S, Honda M, Nozoe T and Korenaga D: Overexpression of cyclin B1 in gastric cancer and its clinicopathological significance: an immunohistological study. J Cancer Res Clin Oncol 128: 412-416, 2002.

40. Nelson AR, Fingleton B, Rothenberg ML and Matrisian LM: Matrix metalloproteinases: biologic activity and clinical implications. J Clin Oncol 18: 1135-1149, 2000.

41. Shiomi T and Okada Y: MT1-MMP and MMP-7 in invasion and metastasis of human cancers. Cancer Met Rev 22: 145-152, 2003.

42. Adachi Y, Yamamoto H, Itoh F, Hinoda Y, Okada Y and Imai K: Contribution of matrilysin (MMP-7) to the metastatic pathway of human colorectal cancers. Gut 45: 252-258, 1999

43. Yamamoto H, Adachi Y, Itoh F, Iku S, Matsuno K, Kusano M, Arimura Y, Endo T, Hinoda Y, Hosokawa M and Imai K: Association of matrilysin expression with recurrence and poor prognosis in human esophageal squamous cell carcinoma. Cancer Res 59: 3313-3316, 1999.

44. Ajisaka H, Yonemura Y and Miwa K: Correlation of lymph node metastases and expression of matrix metalloproteinase-7 in patients with gastric cancer. Hepatogastroenterology 51: 900-905, 2004

45. Aihara R, Mochiki E, Kamiyama Y, Ohno T, Asao T and Kuwano H: Matrilsin expression is a useful marker of submucosal invasion and lymph node metastasis in early stage signet ring cell carcinoma of the stomach. J Surg Oncol 93: 491-497, 2006.

46. Steeg PS, Bevilacqua G, Kopper L, Thorgeirsson UP Talmadge JE, Liotta LA and Sobel ME: Evidence for a novel gene associated with low tumor metastatic potential. J Natl Cancer Inst 80: 200-204, 1988 .

47. Hirayama R, Sawai S, Takagi Y, Mishima Y, Kimura N Shimada N, Esaki $Y$, Kurashima C, Utsuyama $M$ and Hirokawa K: Positive relationship between expression of antimetastatic factor (nm23 gene product or nucleoside diphosphate kinase) and good prognosis in human breast cancer. J Nat Cancer Inst 83: 1249-1250, 1991

48. Campo E, Miquel R, Jares P, Bosch F, Juan M, Leone A Vives J, Cardesa A and Yague J: Prognostic significance of the loss of heterozygosity of Nm23-H1 and p53 genes in human colorectal carcinomas. Cancer 73: 2913-2921, 1994.

49. Nakayama T, Ohtsuru A, Nakao K, Shima M, Nakata K Watanabe K, Ishii N, Kimura N and Nagataki S: Expression in human hepatocellular carcinoma of nucleoside diphosphate kinase, a homologue of the nm23 gene product. J Natl Cancer Inst 84: 1349-1354, 1992 .

50. Bosnar MH, Pavelic K, Krizanac S, Slobodnjak Z and Pavelic J: Squamous cell lung carcinomas: the role of nm23-H1 gene. J Mol Med 75: 609-613, 1997.

51. Engel M, Theisinger B, Seib T, Seitz G, Huwer H, Zang KD, Welter C and Dooley S: High levels of nm23-H1 and nm23-H2 messenger RNA in human squamous-cell lung carcinoma are associated with poor differentiation and advanced tumor stages. Int J Cancer 55: 375-379, 1993.

52. Kodera Y, Isobe K, Yamauchi M, Kondoh K, Kimura N, Akiyama S, Itoh K, Nakashima I and Takagi H: Expression of nm23 H-1 RNA levels in human gastric cancer tissues. A negative correlation with nodal metastasis. Cancer 73: 259-265, 1994.

53. Hsu NY, Chow KC, Chen WJ, Lin CC, Chou FF and Chen CL: Expression of $\mathrm{nm} 23$ in the primary tumor and the metastatic regional lymph nodes of patients with gastric cardiac cancer. Clin Cancer Res 5: 1752-1757, 1999

54. Muller W, Schneiders A, Hommel G and Gabbert HE: Expression of nm23 in gastric carcinoma: association with tumor progression and poor prognosis. Cancer 83: 2481-2487, 1998.

55. Monig SP, Nolden B, Lubke T, Pohl A, Grass G, Schneider PM, Dienes HP, Holscher AH and Baldus SE: Clinical significance of nm23 gene expression in gastric cancer. Anticancer Res 27: 3029-3033, 2007.

56. Nakashima M, Sonoda $\mathrm{K}$ and Watanabe $\mathrm{T}$ : Inhibition of cell growth and induction of apoptotic cell death by the human tumor-associated antigen RCAS1. Nat Med 5: 938-942, 1999.
57. Okada K, Nakashima M, Komuta K, Hashimoto S, Okudaira S, Baba N, Hishikawa Y, Koji T, Kanematsu T and Watanabe T: Expression of tumor-associated membrane antigen, RCAS1, in human colorectal carcinomas and possible role in apoptosis of tumor-infiltrating lymphocytes. Mod Pathol 16: 679-685, 2003.

58. Iwasaki T, Nakashima M, Watanabe $T$, Yamamoto $S$, Inoue $Y$, Yamanaka H, Matsumura A, Iuchi K, Mori T and Okada M: Expression and prognostic significance in lung cancer of human tumor-associated antigen RCAS1. Int J Cancer 89: 488-493, 2000.

59. Nakamura Y, Yamazaki K, Oizumi S, Nakashima M, Watanabe T, Dosaka-Akita $\mathrm{H}$ and Nishimura M: Expression of RCAS1 in human gastric carcinoma: a potential mechanism of immune escape. Cancer Sci 95: 260-265, 2004.

60. Fukuda K, Tsujitani S, Maeta Y, Yamaguchi K, Ikeguchi M and Kaibara N: The expression of RCAS1 and tumor infiltrating lymphocytes in patients with T3 gastric carcinoma. Gastric Cancer 5: 220-227, 2002.

61. Duffy MJ, O'Donovan N, Brennan DJ, Gallagher WM and Ryan BM: Survivin: a promising tumor biomarker. Cancer Lett 249: 49-60, 2007.

62. Altieri DC: New wirings in the survivin networks. Oncogene 27: 6276-6284, 2008

63. Miyachi K, Sasaki K, Onodera S, Taguchi T, Nagamachi M, Kaneko $\mathrm{H}$ and Sunagawa $\mathrm{M}$ : Correlation between survivin mRNA expression and lymph node metastasis in gastric cancer. Gastric Cancer 6: 217-224, 2003.

64. Lee GH, Joo YE, Koh YS, Chung IJ, Park YK, Lee JH, Kim HS, Choi SK, Rew JS, Park CS and Kim SJ: Expression of survivin in gastric cancer and its relationship with tumor angiogenesis. Eur J Gastroenterol Hepatol 18: 957-963, 2006.

65. Krieg A, Mahotka C, Krieg T, Grabsch H, Muller W, Takeno S, Suschek CV, Heydthausen M, Gabbert HE and Gerharz CD: Expression of different survivin variants in gastric carcinomas: first clues to a role of survivin-2B in tumour progression. $\mathrm{Br} \mathrm{J}$ Cancer 86: 737-743, 2002.

66. Lu CD, Altieri DC and Tanigawa N: Expression of a novel antiapoptosis gene, survivin, correlated with tumor cell apoptosis and p53 accumulation in gastric carcinomas. Cancer Res 58: 1808-1812, 1998

67. Okada E, Murai Y, Matsui K, Isizawa S, Cheng C, Masuda M and Takano Y: Survivin expression in tumor cell nuclei is predictive of a favorable prognosis in gastric cancer patients. Cancer Lett 163: 109-116, 2001

68. Japanese Gastric Cancer Association: Japanese Classification of Gastric Carcinoma, 2nd English edition. Gastric Cancer 1: 10-24, 1998.

69. Gunthert U, Hofmann M, Rudy W, Reber S, Zoller M, Haussmann I, Matzku S, Wenzel A, Ponta H and Herrlich P: A new variant of glycoprotein CD44 confers metastatic potential to rat carcinoma cells. Cell 65: 13-24, 1991.

70. Harada N, Mizoi T, Kinouchi M, Hoshi K, Ishii S, Shiiba K, Sasaki I and Matsuno S: Introduction of antisense CD44S CDNA down-regulates expression of overall CD44 isoforms and inhibits tumor growth and metastasis in highly metastatic colon carcinoma cells. Int J Cancer 91: 67-75, 2001.

71. Wielenga VJ, Heider KH, Offerhaus GJ, Adolf GR, van den Berg FM, Ponta H, Herrlich P and Pals ST: Expression of CD44 variant proteins in human colorectal cancer is related to tumor progression. Cancer Res 53: 4754-4756, 1993.

72. Wilson CL and Matrisian LM: Matrilysin: an epithelial matrix metalloproteinase with potentially novel functions. Int J Biochem Cell Biol 28: 123-136, 1996.

73. Ii M, Yamamoto H, Adachi Y, Maruyama Y and Shinomura Y: Role of matrix metalloproteinase-7 (matrilysin) in human cancer invasion, apoptosis, growth, and angiogenesis. Exp Biol Med (Maywood) 231: 20-27, 2006.

74. Correa P: Human gastric carcinogenesis: a multistep and multifactorial process-First American Cancer Society Award Lecture on Cancer Epidemiology and Prevention. Cancer Res 52: 6735-6740, 1992 .

75. Liu Q, Teh M, Ito K, Shah N, Ito Y and Yeoh KG: CDX2 expression is progressively decreased in human gastric intestinal metaplasia, dysplasia and cancer. Mod Pathol 20: 1286-1297, 2007. 